\title{
Letter to the editor: Seafarers: a new risk group for meticillin-resistant Staphylococcus aureus (MRSA)
}

W S Lekkerkerk (w.lekkerkerk@erasmusmc.nl)1, P J van Genderen², J A Severin¹, J P Peper ${ }^{1}$, E F Storm¹, M C Vos ${ }^{1}$

1. Erasmus MC, University Medical Center Rotterdam, Department of Medical Microbiology and Infectious Diseases, the Netherlands

2. Harbour Hospital, Institute for Tropical Diseases, Rotterdam, the Netherlands

Citation style for this article:

Lekkerkerk WS, van Genderen PJ, Severin JA, Peper JP, Storm EF, Vos MC. Letter to the editor: Seafarers: a new risk group for meticillin-resistant Staphylococcus aureus (MRSA). Euro Surveill. 2013;18(43):pii=20618. Available online: http://www.eurosurveillance.org/ViewArticle.aspx?Articleld=20618

Article submitted on 08 October 2013 / published on 24 October 2013

To the editor: We applaud the successful implementation of meticillin-resistant Staphylococcus aureus (MRSA) screening programme on the German side of the Dutch-German border region (EUREGIO) [1]. The described strategy is based on the risk-based admission screening approach [1].

From our experience with 'search and destroy' (S and D) in the Netherlands, we learned that it is essential to evaluate and timely enlarge risk categories when epidemiology changes to prevent MRSA of unknown origin (MUO), i.e. not fitting any defined risk factors [2]. Herewith, we report our recent finding of a previously unrecognised risk group for MRSA: seafarers.

In 2010, we noticed that clinical cultures with unexpected MRSA in the Harbour Hospital (Port of Rotterdam, the Netherlands) were mainly from seafarers. Although the Harbour Hospital is especially equipped for seafarers, this patient population only accounts for $1.2 \%$ of all admissions [3]. Since seafarers are not considered an MRSA risk group, all seafarer patients were screened (nose and throat) at the Emergency Department of the Harbour Hospital in a six month prospective surveillance (2011). Perineum and wounds were screened additionally, if active infection or skin lesions were present. Detection of MRSA was performed as previously described [4], and spa typing was done at the reference laboratory of the National Institute for Public Health and the Environment (RIVM) [5]. Furthermore, since the hospital is visited by a large number of seafarers, a case-control study was designed to identify risk factors for MRSA carriage among seafarers, in order to identify specific risk factors within this putative new risk group.

Cases were defined as seafarers with a positive MRSA culture of any site, whereas controls had a negative MRSA culture. Data on demographics, medical history, laboratory and naval parameters were collected retrospectively. Data were then analysed by univariate (chisquared, Fisher's exact test) and multivariate analysis (logistic regression model).
In the study period 124 seafarers (men, 22-51 years of age) were included. Four seafarer patients had an unknown MRSA status and were excluded. MRSA prevalence among seafarers was 5.8\% (95\% confidence interval $(\mathrm{Cl}): 4.6-7.1)$ and the incidence rate was 24.8/1,000 seafarer population. Seven MRSA-positive seafarers were identified as cases, leaving 113 MRSAnegative seafarers as controls. Of seven MRSA carriers, four had wounds, of which three were cultured MRSA positive as well. Furthermore, of seven MRSA strains, five had similar spa repeat successions: to19 (twice), t122, t975 and t4557. The remaining two were t4845 and t9231. Nationality was only known for 32 seafarers.

TABLE

Risk factors for meticillin-resistant Staphylococcus aureus (MRSA) in seafarers, Rotterdam, the Netherlands

\begin{tabular}{|c|c|c|c|c|}
\hline Risk factor & $\begin{array}{c}\text { MRSA } \\
\text { positive } \\
(\mathrm{N}=7) \\
\mathrm{n}(\%)\end{array}$ & $\begin{array}{c}\text { MRSA } \\
\text { negative } \\
(\mathrm{N}=113) \\
\mathrm{n}(\%)\end{array}$ & P-value & $\begin{array}{l}\text { Odds ratio } \\
(95 \% \mathrm{Cl})\end{array}$ \\
\hline Male sex & $7(100)$ & 112 (99) & - & - \\
\hline \multicolumn{5}{|c|}{ Specialist involved with patient } \\
\hline Internal medicine & $2(29)$ & 21 (19) & 0.61 & - \\
\hline Surgery & $5(71)$ & $59(52)$ & 0.45 & - \\
\hline \multicolumn{5}{|c|}{ Physical examination } \\
\hline $\begin{array}{l}\text { Presence of } \\
\text { wounds or } \\
\text { abscesses }\end{array}$ & $4(57)$ & $5(4)$ & $<0.01$ & $\begin{array}{c}40.8 \\
(5.9-278.3)\end{array}$ \\
\hline Pus detected & $2(28)$ & $2(2)$ & 0.01 & $\begin{array}{c}26.7 \\
(2.9-241.3)\end{array}$ \\
\hline
\end{tabular}

$\mathrm{Cl}$ : confidence interval; OR: odds ratio.

Presence of wounds or abscesses was the only risk factor $(p<0.01)$ in univariate analysis and in the multiple regression model with an OR of 40.8 (95\% Cl: $5.9-278.3)$. The multiple regression model was based on forward selection with 'presence of wounds or abscesses', 'detection of pus' and 'C-reactive protein (CRP)' (area under the receiver operator characteristic criterion (AUC): 0.75 , R2max: 0.4603). 
Twenty-five of them were of Asian origin, with 18 seafarers from the Philippines. Of MRSA carriers, nationality was known in two cases: the Philippines and India.

Severe missing data for many proposed variables forced us to exclude many variables, as registration of seafarers was basic due to swift departure and communication difficulties. The remaining risk factors are listed in the Table. Presence of wounds or abscesses was the only significant risk factor ( $p<0.01$ ) in both univariate analysis and multivariate regression analysis (odds ratio (OR): 40.8 (95\% Cl: 5.9-278.3)). The multivariate regression model was based on forward selection with 'presence of wounds or abscesses', 'detection of pus' and 'C-reactive protein (CRP)' (area under the receiver operator characteristic criterion (AUC): 0.75 , R2max: 0.4603). The positive predictive value for finding an MRSA carrier when a seafarer had a wound was $44 \%$ whereas the negative predictive value (MRSA carrier when a seafarer has no wound) was $2 \%$. The MRSA carriage did not influence the duration of hospitalisation of the seafarers $(p=0.36)$.

In our limited sample of 124 seafarers, the $5.8 \%$ MRSA prevalence detected is 52-times higher than the normal prevalence in the Netherlands (0.11\% at hospital admission) [4], and the presence of wounds or abscesses gave a 40-times higher risk of being MRSA positive. Some bias might play a role due to our screening procedure. However, this choice was made due to communication difficulties and cultural differences.

Given the high prevalence rate of carriage among seafarers, we recommend that all seafarers should be screened for MRSA in the Netherlands, regardless of wounds or underlying disease, and to apply pre-emptive isolation while awaiting test results, and should be taken into consideration as risk group by other European nations. Further studies are necessary to understand the impact of global transmission of MRSA clones by seafarers.

\section{Acknowledgements}

We acknowledge Wilma A. Stolk, Marijn Bennaars, Wouter van der Steen, Tim van der Torre, Linda Vriend, the infection preventionists of the Erasmus MC and Harbour Hospital and the Harbour Hospital Emergency Department personnel for their work.

\section{Conflict of interest}

None declared.

\section{Authors' contributions}

Jeroen Peper and Eline Storm collected data. Wouter Lekkerkerk analyzed data and wrote the manuscript. Juliëtte Severin supervised the prospective study and reviewed the manuscript. Perry van Genderen, Margreet Vos supervised overall and reviewed the manuscript.
References

1. Jurke A, Kock R, Becker K, Thole S, Hendrix R, Rossen J, et al. Reduction of the nosocomial meticillin-resistant Staphylococcus aureus incidence density by a region-wide search and follow-strategy in forty German hospitals of the EUREGIO, 2009 to 2011. Euro Surveill. 2013;18(36): pii=20579. Available from: http://www.eurosurveillance.org/ViewArticle. aspx?Articleld=20579. PMid:24079380.

2. Lekkerkerk WS, van de Sande-Bruinsma N, van der Sande MA, Tjon-A-Tsien A, Groenheide A, Haenen A, et al. Emergence of MRSA of unknown origin in the Netherlands. Clin Microbiol Infect. 2012;18(7):656-61. http://dx.doi.org/10.1111/j.14690691.2011.03662.x. PMid:21967090.

3. Havenkrant. Ziek op zee en 10.000 kilometer van huis [Sick at sea and 10,000 kilometers from home]. December 2012. [Accessed 1 Jul 2013]. Dutch. Available from: http://www. portofrotterdam.com/nl/actueel/Havenkrant/Documents/ Havenkrant-16-2012/files/assets/basic-html/page4.html

4. Bode LG, Wertheim HF, Kluytmans JA, Bogaers-Hofman D, Vandenbroucke-Grauls CM, Roosendaal R, et al. Sustained low prevalence of meticillin-resistant Staphylococcus aureus upon admission to hospital in The Netherlands. J Hosp Infect. 2011;79(3):198-201.

http://dx.doi.org/10.1016/j.jhin.2011.05.009. PMid:21763031.

5. Harmsen D, Claus H, Witte W, Rothganger J, Turnwald D, Vogel U. Typing of methicillin-resistant Staphylococcus aureus in a university hospital setting by using novel software for spa repeat determination and database management. J Clin Microbiol. 2003;41(12):5442-8.

http://dx.doi.org/10.1128/JCM.41.12.5442-5448.2003. PMid:14662923. PMCid:PMC309029. 